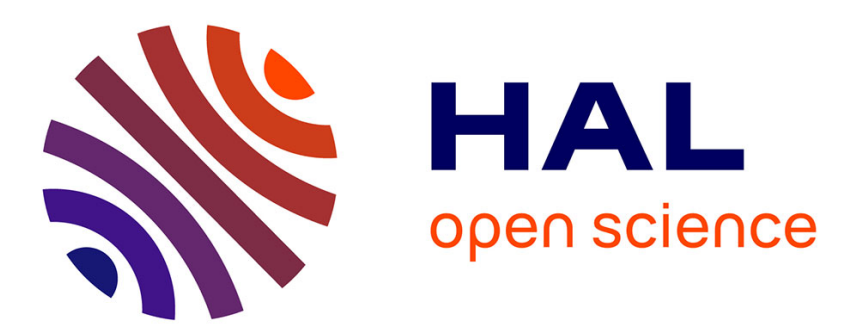

\title{
Growth kinetics and origin of residual stress of two-phase crystalline-amorphous nanostructured films
}

\author{
A. Borroto, S. Bruyère, S. Migot, J. F Pierson, F. Mücklich, David Horwat
}

\section{To cite this version:}

A. Borroto, S. Bruyère, S. Migot, J. F Pierson, F. Mücklich, et al.. Growth kinetics and origin of residual stress of two-phase crystalline-amorphous nanostructured films. Journal of Applied Physics, 2021, 129 (14), pp.145301. 10.1063/5.0044029 . hal-03278772

\section{HAL Id: hal-03278772 \\ https://hal.science/hal-03278772}

Submitted on 5 Jul 2021

HAL is a multi-disciplinary open access archive for the deposit and dissemination of scientific research documents, whether they are published or not. The documents may come from teaching and research institutions in France or abroad, or from public or private research centers.
L'archive ouverte pluridisciplinaire HAL, est destinée au dépôt et à la diffusion de documents scientifiques de niveau recherche, publiés ou non, émanant des établissements d'enseignement et de recherche français ou étrangers, des laboratoires publics ou privés. 


\title{
Growth kinetics and origin of residual stress of two-phase crystalline-amorphous nanostructured films
}

\author{
A. Borroto, ${ }^{1,2}$, a) S. Bruyère, ${ }^{1}$ S. Migot, ${ }^{1}$ J.F. Pierson, ${ }^{1}$ F. Mücklich, ${ }^{2}$ and D. Horwat ${ }^{1, b)}$ \\ 1) Université de Lorraine, CNRS, IJL, F-54000 Nancy, France. \\ ${ }^{2)}$ Department of Materials Science and Engineering, Chair of Functional Materials, Saarland University, \\ Campus D3.3, D-66123 Saarbrücken, Germany.
}

(Dated: 4 March 2021)

Composition-driven amorphous-to-crystalline transition is widely observed in sputter-deposited thin films. We have recently shown that peculiar two-phase crystalline-amorphous nanostructures can be obtained for compositions in the transition zone between single-phased amorphous and crystalline films, offering a new possibility to control surface topography and related functional properties. Here, the growth kinetics of the two-phase nanostructures formed in the transition zone is explored and related to residual stress measurements. From the analysis of top-view scanning electron microscopy images, the evolution with the film thickness of relevant parameters describing the growth process was extracted, i.e., surface coverage, volume fraction and perimeter per unit area of the crystalline regions growing in competition with the amorphous ones. We demonstrate, supported in the aforementioned parameters, that residual stress evolution in the transition zone is governed by the nucleation, growth and interaction of the crystalline regions during the competitive growth process. Our results shed new light on the kinetics of the crystalline-amorphous competitive growth phenomenon and demonstrate the relevance of residuals stress measurements for exploring the growth mechanisms of complex film microstructures.

\section{INTRODUCTION}

Understanding the origin of residual stresses in thin films is of crucial importance in various practical applications. High levels of residual stress can be detrimental to the mechanical stability and adhesion of the film to the substrate, resulting in cracking and delamination ${ }^{1-4}$. In this sense, an interesting strategy for stress reduction consist in the growth of a nanostructured compliant layer of a low-density material sandwiched between the film and the substrate ${ }^{5,6}$. In addition to the pragmatic problem of preserving film quality, residual stress can directly influence many of the film's properties, such as mechanical ${ }^{7,8}$, magnetic ${ }^{9,10}$, optical ${ }^{11}$ or electrical ${ }^{12}$, to cite a few. As in first instance is the microstructure which determines the properties, establishing a link between residual stress and microstructure is of primordial importance and has been the object of many publication through the years. A good example of this are the well-known structure zone models $(\mathrm{SZM})^{13-16}$, which relate the most relevant deposition conditions (workinggas pressure, substrate temperature, or any other parameter causing a transfer of energy and/or momentum to the atoms arriving at the film surface) with the microstructure of the deposited film. Effectively, it has been largely observed that increasing the working gas pressure in sputter-deposited films, a transition from a denser (zone T) to a porous and columnar (zone 1) microstructure occurs which is associated to a change of residual stress from compressive to tensile ${ }^{17-22}$. More

\footnotetext{
a) Electronic mail: alejandro.borroto@univ-lorraine.fr

b) Electronic mail: david.horwat@univ-lorraine.fr
}

recently, many studies have focused on the evolution of stress in the early-stages of film growth, greatly advancing the understanding of the atomic-level mechanisms of stress generation ${ }^{23-27}$. Overall, in most of these studies, mono-phased films are considered, and reports relating the evolution of residual stress during the growth of films with multi-phased microstructures are still scarce. Additional efforts are needed to define parameters at the origin of stress built-up in such films, which is at the core of the present study.

In previous works ${ }^{28,29}$, we reported on the mechanisms of competitive growth between amorphous and crystalline phases in thin films, leading to original microstructures consisting of a crystalline phase of featherlike morphology embedded in an amorphous matrix. By working at compositions in the transition zone between those needed to obtain single-phased amorphous or crystalline films, the desired microstructure is obtained as a consequence of the competitive growth of the amorphous and the crystalline phases. Thereby, surface-dependent functional properties, such as optical reflectivity and wettability can be manipulated to a large extent. Although these studies primarily focused on the binary Zr-Mo and $\mathrm{Zr}-\mathrm{W}$ systems, similar microstructures have been observed in $\mathrm{Ti}-\mathrm{Al}^{30}$, $\mathrm{Ti}-\mathrm{O}^{31}$ and $\mathrm{Al}-\mathrm{N}^{32}$ films, suggesting the possibility to generalize the concept. Other authors have recently reported the phenomenon in the $\mathrm{Zr}-\mathrm{W}$ system using different deposition conditions ${ }^{33}$. Moreover, we have also shown that it occurs under a wide range of deposition conditions. For instance, the shape of the crystalline domains can be modified by selecting low or high pressure conditions ${ }^{28}$. In this crystalline-amorphous competitive growth process, the crystalline and amorphous regions can easily be identified and the kinetics of the competitive growth can be modeled through access to 


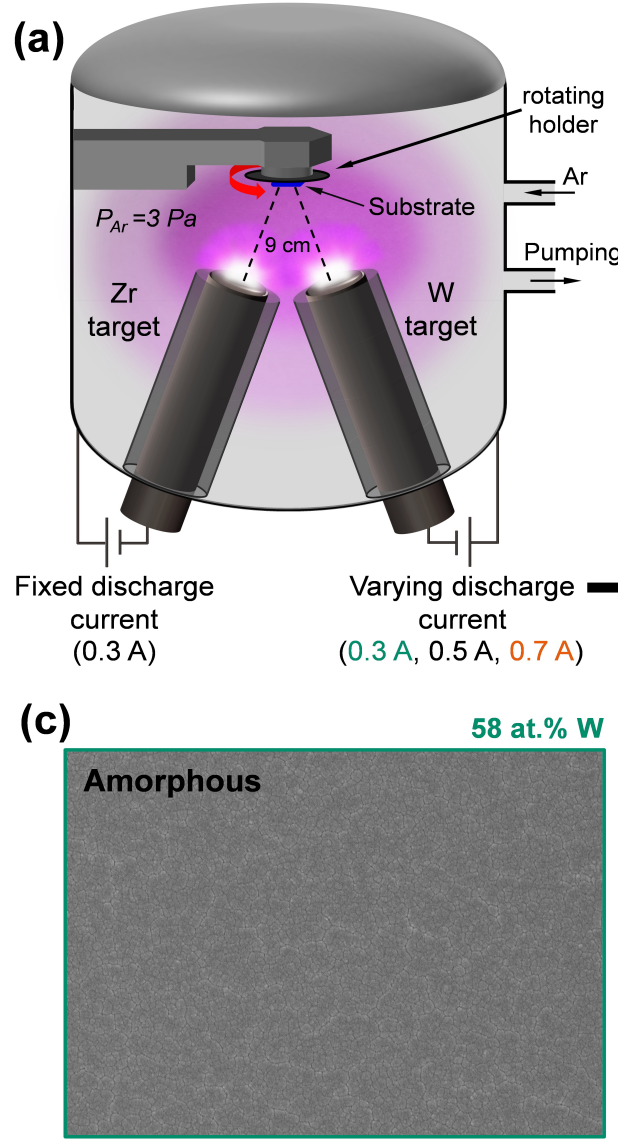

(b)
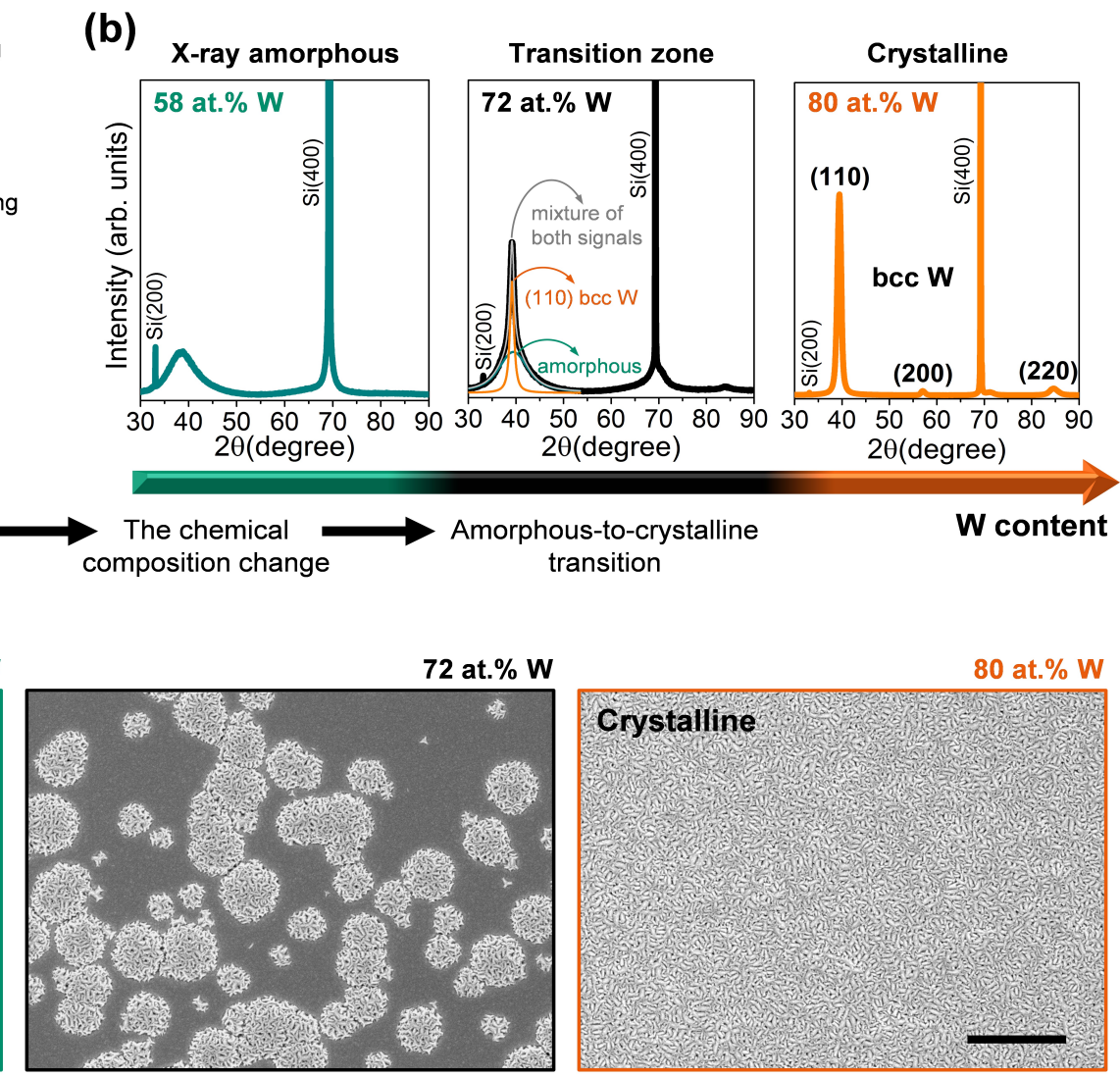

FIG. 1. Amorphous-to-crystalline transition in sputter-deposited $\mathrm{Zr}-\mathrm{W}$ thin films. (a) Schematic of the sputtering chamber showing the experimental conditions used to obtain the alloys. By varying the discharge current applied to the cathodes, the chemical composition of the films can be controlled. (b) X-ray diffractograms of the films $(\sim 1000 \mathrm{~nm}$ thick $)$ revealing the structural transition associated to the change in composition. Increasing the $\mathrm{W}$ content, the films structure evolves from amorphous (at 58 at.\% W) to crystalline (at 80 at.\% W). In the transition zone (at 72 at.\% W) the X-ray signal is a mixture of the amorphous and crystalline signals. (c) Top view SEM images of the films revealing the separation of the amorphous and crystalline phases occurring in the transition zone. Scale bar: $1 \mu \mathrm{m}$.

the shape of crystalline regions. Hence, this type of films can serve as a platform to understand and model stressmicrostructure evolution in nanostructured thin films.

Here, we continue the exploration of these peculiar two-phase crystalline-amorphous nanostructures. Using $\mathrm{Zr}-\mathrm{W}$ thin films as a model system, new insights into the kinetics of this phenomenon are presented. In particular, the growth kinetics of the obtained two-phase nanostructures is linked with residual stress measurements.

\section{EXPERIMENTAL DETAILS}

Thin films synthesis: $\mathrm{Zr}-\mathrm{W}$ thin film alloys were obtained by $\mathrm{DC}$ magnetron co-sputtering of $\mathrm{Zr}$ and $\mathrm{W}$ metallic targets in the presence of argon (see Fig. 1a). The films were deposited on (100) silicon single crystal substrates. The depositions were made with the substrate holder in rotation mode in order to ensure a good lateral homogeneity of the film composition and thick- ness. The sputtering chamber was pumped down via a mechanical and a turbo-molecular pump allowing a base vacuum of $10^{-6} \mathrm{~Pa}$. The cathodes were mounted in a confocal configuration and the targets to substrate distance was fixed at $9 \mathrm{~cm}$. An argon flow rate of $30 \mathrm{sccm}$ and a working argon pressure of $3 \mathrm{~Pa}$ were used. Zirconium and tungsten targets $(50.8 \mathrm{~mm}$ diameter, $3 \mathrm{~mm}$ thick and purity higher than $99.9 \%$ ) were powered by an Maxim 1000 DC generator. A fixed discharge current of $0.3 \mathrm{~A}$ was applied to the $\mathrm{Zr}$ target meanwhile the discharge current applied to the $\mathrm{W}$ target was varied from 0.3 to $0.7 \mathrm{~A}$ between experiments and depending on the desired chemical composition of the films. The films were deposited without external heating. The self-established temperature at the substrate was measured using a thermocouple and did not exceed $55^{\circ} \mathrm{C}$ during growth.

Thin films characterization: X-ray diffraction (XRD) measurements were conducted in the Bragg-Brentano configuration with $\mathrm{K}_{\alpha} \mathrm{Cu}$ radiation $(\lambda=1.5406 \AA)$ using an AXS Bruker D8 Advance diffractometer. Transmis- 
sion electron microscopy (TEM) analysis was performed using a cold FEG JEOL ARM200 microscope. Crosssectional TEM samples of films were prepared using a focused ion beam (FIB)-scanning electron microscope dual beam system (FEI Helios 600). Throughout the FIB process, the time during the ionic cuts was the shortest possible to avoid any heating effect. Top and cross-sectional scanning electron micrographs of the films were taken in a Philips XL-30 S-FEG scanning electron microscope (SEM) using an accelerating voltage of $3 \mathrm{kV}$.

Residual stress measurements: The residual stress of films deposited on $\mathrm{Si}(100)$ substrates of $0.5 \times 2.5 \mathrm{~cm}^{2}$ was determined using the Stoney's equation ${ }^{34}$ :

$$
\sigma=\frac{M_{s}}{6} \frac{h_{s}^{2}}{h_{f}}\left(\frac{1}{R}-\frac{1}{R_{0}}\right)
$$

where $h_{f}$ is the film thickness, $h_{s}$ is the substrate thickness $(200 \mu \mathrm{m}), M_{s}=180.3 \mathrm{GPa}$ is the biaxial modulus of the substrate, $R_{0}$ is the curvature radius of the substrate before the film deposition and $R$ is the curvature radius after the film deposition. Film thicknesses and curvature radii were measured using a DektakXT BRUKER profilometer.

Processing of top view SEM images: Surface coverage by the nanocrystalline phase was determined using the software Image J by processing the top view SEM images. The procedure followed is briefly described here (for more details see $\left.{ }^{29}\right)$. First, a Bandpass Filter was applied to the SEM image, which allows better delimiting the nanocrystalline and amorphous phases. After, a careful selection of a Threshold was done, allowing us to obtain a black and white image. Then, the boundaries delimiting neighboring nanocrystalline nuclei in contact were manually marked. This permits to apply a Fill Holes function, yet keeping the nanocrystalline nuclei correctly separated. After that, the surface coverage could be calculated straightforwardly using the software.

\section{RESULTS AND DISCUSSION}

\section{A. Two-phase crystalline-amorphous nanostructures in the Zr-W system: kinetics}

In sputter-deposited $\mathrm{Zr}-\mathrm{W}$ thin film alloys synthesized without thermal assistance, a transition from an amorphous to a nanocrystalline structure is expected upon increasing the $\mathrm{W}$ content $^{35,36}$. By changing the discharge current applied to one of the targets (Fig. 1a), the chemical composition of the alloy can be controlled. This change in composition results in films with different structural features (Fig. 1b). Effectively, the X-ray diffractogram of films presenting 58 at. $\% \mathrm{~W}$ shows a wide hump, characteristic of the amorphous phase (Fig. 1b, left). On the other hand, films with 80 at. $\% \mathrm{~W}$ show well-defined diffraction peaks, which can be ascribed to the bcc phase of W (Fig. 1b, right). This compositiondriven transition from a single-phased amorphous to a

\section{(a)}
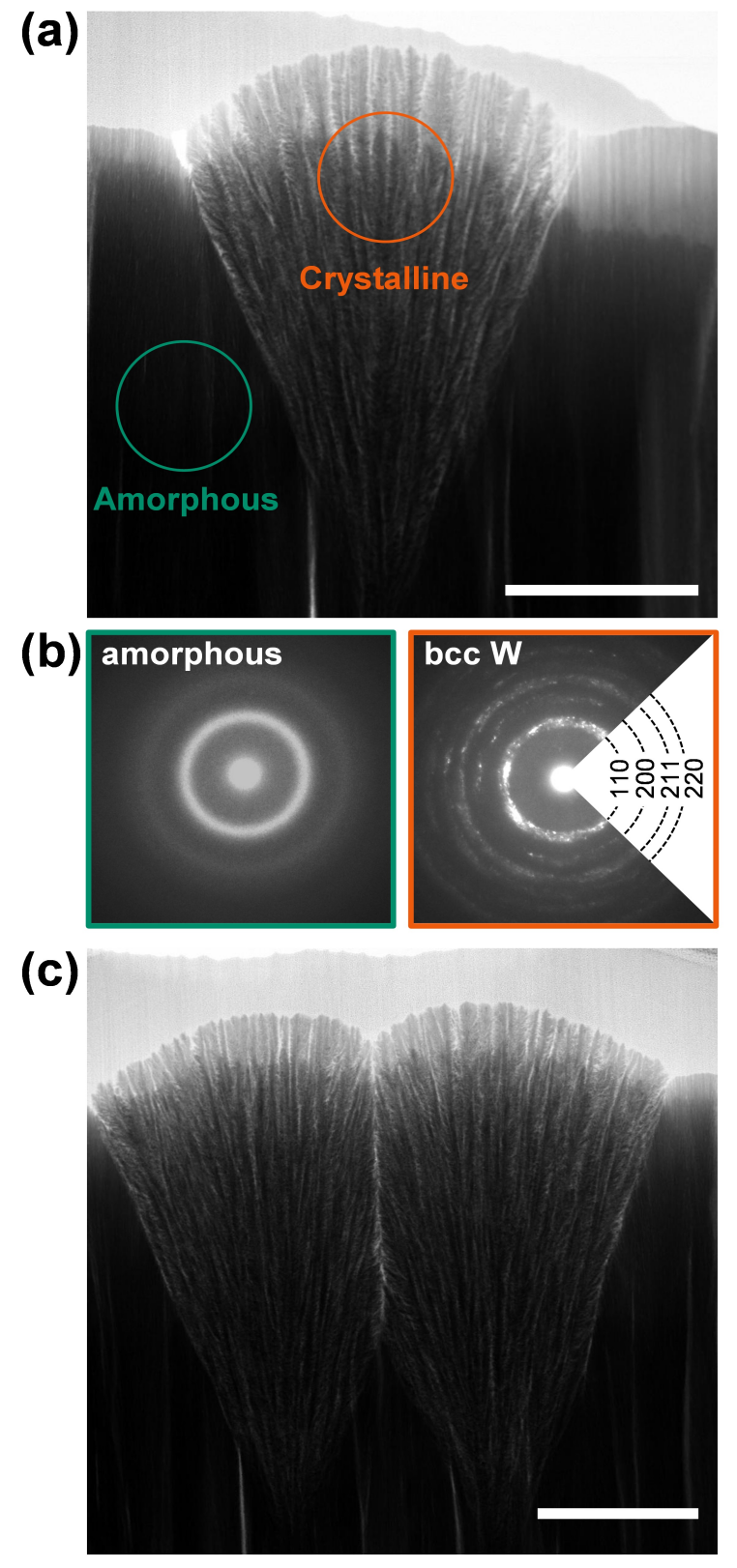

FIG. 2. TEM investigation of $\mathrm{Zr}-\mathrm{W}$ film obtained in the amorphous-to-crystalline transition zone. (a) Bright-field TEM image showing an isolated cone-like crystalline region. Scale bar: $500 \mathrm{~nm}$. (b) Selected area electron diffraction (SAED) patterns of the zones highlighted in (a). (c) Brightfield TEM image showing two crystalline regions in contact. Scale bar: $500 \mathrm{~nm}$.

single-phased crystalline structure, shown here in the Zr$\mathrm{W}$ system, is characteristic of many sputter-deposited binary alloys ${ }^{37-42}$. As we have recently shown ${ }^{28,29}$, twophase crystalline-amorphous nanostructures can be obtained by working in the transition zone between singlephased amorphous and crystalline films of the Zr-Mo and $\mathrm{Zr}-\mathrm{W}$ systems. The X-ray diffractogram of films grown 
in this zone (Fig. 1b, center) shows a mixture of both (amorphous and crystalline) signals, giving a first indication of their two-phase structure. Interestingly, topview SEM images of the films (Fig. 1c) reveal that in the transition zone, the amorphous (dark contrast) and nanocrystalline (bright contrast) phases are separated in well-defined spatial regions, i.e., amorphous phase acts as a matrix embedding the rounded-shaped nanocrystalline phase.

The bright-field cross-sectional TEM images and selected area electron diffraction patterns for a film grown in the transition zone (Fig. 2) evidence the amorphous and crystalline character of the regions. The crystalline regions are composed by nano-columns. Moreover, it reveals that isolated crystalline regions (Fig. 2a) nucleate in the amorphous matrix and grow as cones with the cone axis oriented along the film growth direction and that these regions terminate by a dome whose base is aligned with the surface of the amorphous matrix. As two crystalline regions contact, an interface is created, truncating the cones (Fig. 2c). The analysis of film cross-section associated and top view SEM images for different thicknesses enables to understand the dynamics of the process. Fig. 3a shows that the film initially grows in an amorphous state and, above a certain thickness (a critical thickness), the nucleation of the nanocrystalline phase starts and both phases continue growing together. In this nanocrystalline-amorphous competitive growth process, the nanocrystalline phase progressively overgrows the amorphous one. An important point in this process is that looking at the surface morphology evolution with thickness (Fig. 3a, top view), the amorphous phase "seems" to be transformed into the nanocrystalline one. This allows to establish an equivalence between the evolution of the surface morphology and a 2-dimensional amorphous-to-nanocrystalline phase transformation $^{29}$. Thus, using the formalism of phase transformations ${ }^{43}$, the surface coverage by the nanocrystalline phase, $S$, can be expressed as a function of the film thickness as follows:

$$
S_{(h)}=1-\left(1+(\xi-1) \chi_{e(h)}\right)^{-1 / \xi-1}
$$

In Eq. (2), $\xi$ is the impingement parameter which takes in consideration the distribution of the nanocrystalline nuclei in the amorphous matrix. When $\xi \longrightarrow 1$, Eq. (2) transforms into $S=1-e^{-\chi e}$, corresponding to the classical Kolmogorov-Johnson-Mehl-Avrami (KJMA) approach, in which a random nucleation of the nanocrystalline phase is assumed ${ }^{44-48}$. For $\xi>1$, impingement of the nanocrystalline phase is stronger, indicating that nucleation occurs at specific sites, such as grain boundaries. $\chi_{e}$ is the so-called extended transformed fraction ${ }^{43,49-51}$, representing, in our case, the projected area, perpendicular to the growth direction of the film, of nanocrystalline regions if they could each nucleate and grow in the absence of interference with other growing nuclei. For the nanocrystalline-amorphous competi-
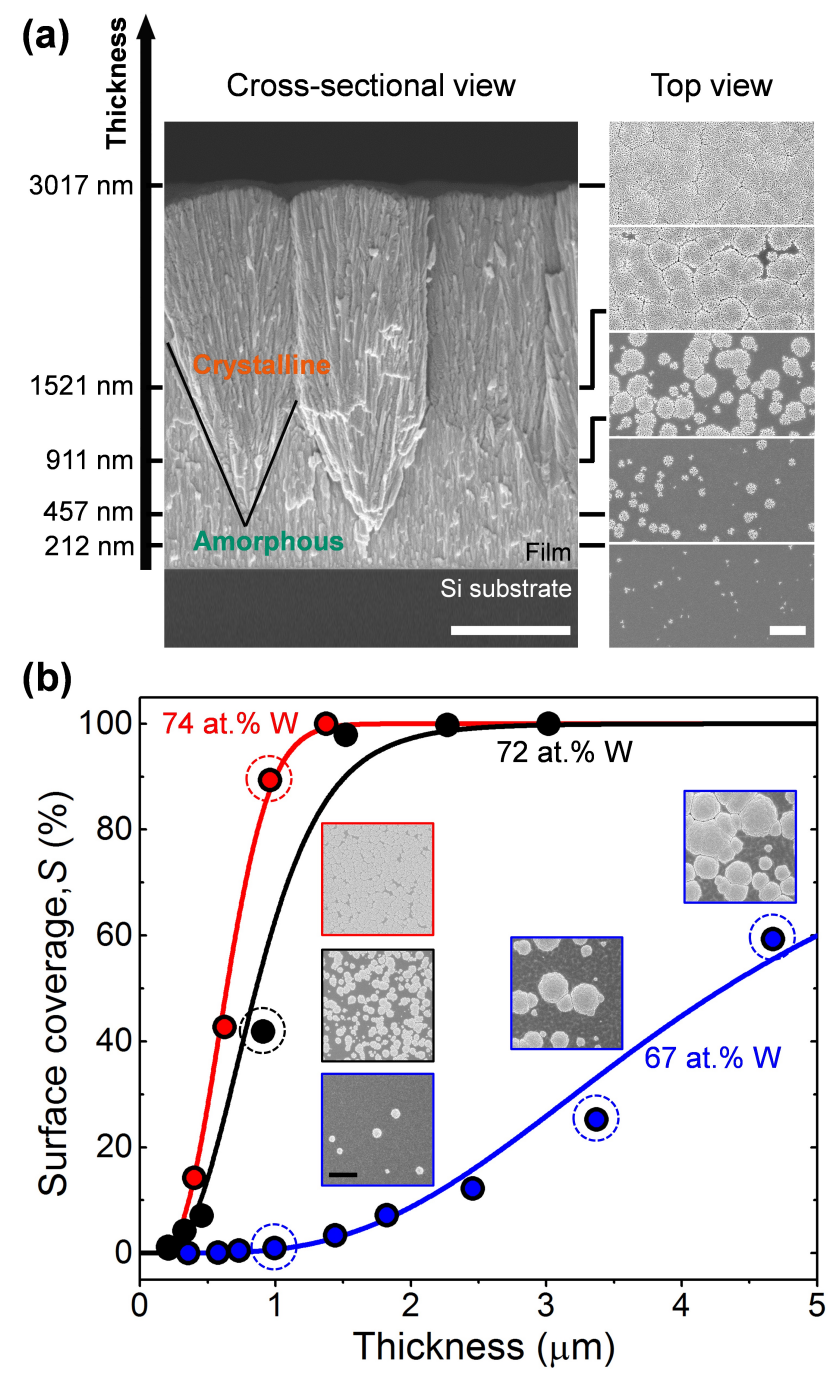

FIG. 3. Morphology evolution in the transition zone. (a) Cross-sectional view (left) and evolution of the surface morphology with thickness (right) of 72 at.\% W film. Scale bar: $1 \mu \mathrm{m}$. (b) Evolution with the film thickness of the surface coverage by the nanocrystalline phase for three compositions in the transition zone: 67 (blue), 72 (black) and 74 (red) at.\% $\mathrm{W}$. The dots represent the experimental data extracted from the analysis of the SEM top views. The lines follow Equation 2 with the parameters shown in Table 1 . Top view images of some films are shown in the figure. Scale bar: $2 \mu \mathrm{m}$.

tive growth process it follows the analytical expression ${ }^{29}$ :

$$
\chi_{e(h)}=\pi\left(\frac{V_{G}}{V_{0}}\right)^{2} \frac{N_{0}}{\gamma^{2}} \Upsilon \Theta\left[h-h_{c}\right],
$$

where $\Upsilon=-2 e^{-\gamma\left(h-h_{c}\right)}+\left(\gamma\left(h-h_{c}\right)-1\right)^{2}+1$. In Eq. (3) $V_{G} / V_{0}$ is the ratio between the growth velocity of the nanocrystalline phase in the in-plane direction $\left(V_{G}\right)$ and the deposition rate of the film $\left(V_{0}\right)$. It can be shown that $V_{G} / V_{0}=0.404^{29} . \quad N_{0}$ is the total number of nanocrystalline nuclei per unit area when all of them are already 

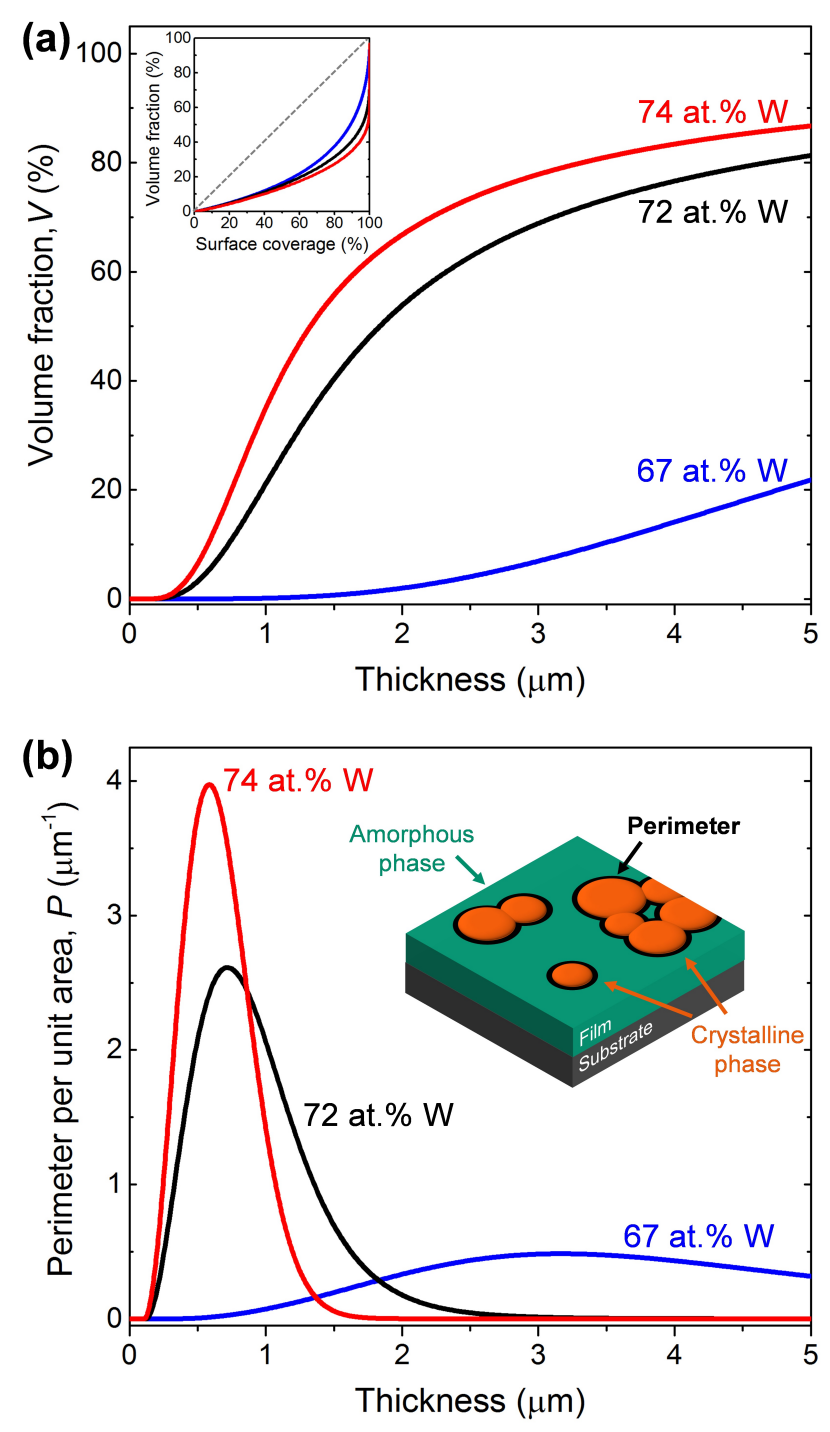

FIG. 4. (a) Evolution of the volume fraction (calculated from Eq. (4)) with the film thickness for the three compositions studied. The inset shows the dependence of the volume fraction with the surface coverage. (b) Evolution of the perimeter per unit area (calculated from Eq. (5)) with the film thickness for the three compositions studied. The geometrical meaning of this parameter is illustrated in the schematic shown in the figure.

nucleated, $\gamma$ is a parameter related with the nucleation rate of the nanocrystalline phase and $\Theta$ is the unitarystep Heaviside function, reflecting the fact that there is a critical thickness, $h_{c}$, from which nucleation starts.

Fig. 3b shows the evolution of $S$ with thickness, extracted from the analysis of the top view SEM images, for three different compositions within the transition zone. SEM images evidence that size and density of nanocrystalline nuclei can be controlled by changing film thickness or composition. Consequently, a variety of surface morphology features can be obtained by changing this two
TABLE I. Fitting parameters. Evolution with W content of the density of nucleation sites $N_{0}, \gamma$, the critical thickness $h_{c}$ and the impingement parameter $\xi$.

\begin{tabular}{ccccc} 
Wcontent $(\mathrm{at} \%)$ & $\mathrm{N}_{0}\left(\mu \mathrm{m}^{-2}\right)$ & $\gamma\left(10^{-3} \mathrm{~nm}^{-1}\right)$ & $\mathrm{h}_{\mathrm{c}}(\mathrm{nm})$ & $\xi$ \\
\hline 67 & 0.34 & 0.41 & 322 & 2.15 \\
72 & 3.74 & 8.33 & 120 & 1.26 \\
74 & 7.92 & 7.19 & 108 & 1.03
\end{tabular}

parameters. The lines in Fig. 3b follow Eq. (2) with the fitted parameters shown in Table I. When the W content increases (approaching to the composition for obtaining single-phase nanocrystalline films), $N_{0}$ increases and $h_{c}$ decreases, indicating more favorable conditions for nucleation. The evolution of $\xi$ between 2 and 1 with the increase of $\mathrm{W}$ content indicates a transition from nucleation at specific sites when conditions for nucleation are more difficult towards random nucleation when more favorable conditions exist.

From Eq. (2), the volume fraction of the nanocrystalline phase inside the film, $V$, can be calculated as follows:

$$
V_{(h)}=\frac{\int_{0}^{h} S_{(h)} d h}{h}
$$

Fig. 4a shows the evolution of $V_{(h)}$ for the three compositions studied. The inset reveals that the values of volume fraction are lower than those of surface coverage, which is due to the geometrical (conical-like) shape of the nanocrystalline regions in the competitive growth process. Another parameter which can be determined supported by Eq. (2) is the perimeter per unit area of the nanocrystalline regions, $P$, whose geometrical meaning is illustrated in the schematic of Fig. $4 \mathrm{~b}$. It can be calculated as:

$$
P_{(h)}=\left(\frac{V_{G}}{V_{0}}\right)^{-1} \frac{\mathrm{d} S}{\mathrm{~d} h}
$$

As can be followed from Fig. 4b, once the critical thickness is reached, $P$ starts to increase due to the nucleation and growth of the nanocrystralline phase, reaches a maximum and then decreases until zero. $P$ decreases due to the coalescence of nanocrystalline regions at late growth stages. Thus, $P$ is a measure of the interaction among these regions. With the increases of the $\mathrm{W}$ content, the maximum value of $P$ increases and is reached at a lower thickness. This is because the density of nanocrystalline nuclei also increases (see $N_{0}$ in Table 1), creating more perimeter per unit area and provoking that the nanocrystalline regions begin to interact earlier. In the following, the evolution of the residual stress in the transition zone will be analyzed supported on the parameters presented so far, i.e. $S, V$ and $P$. 

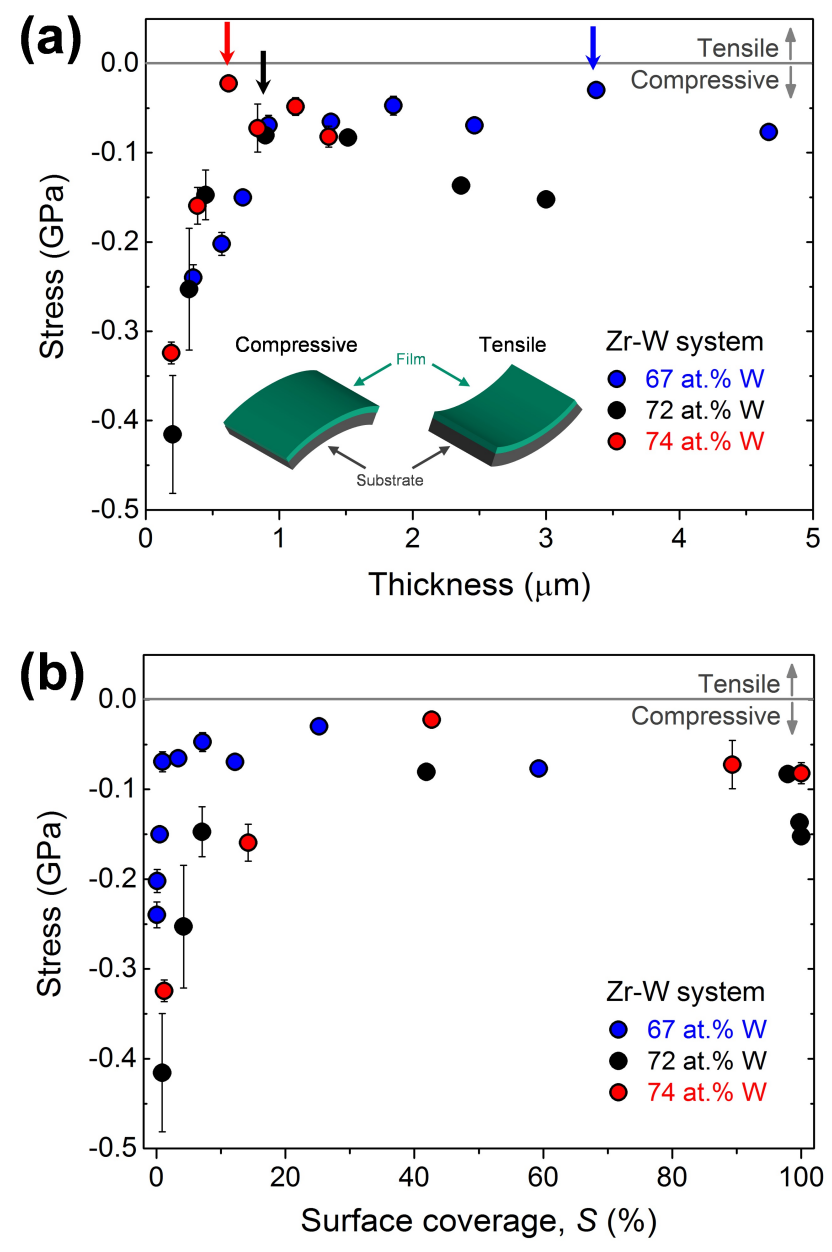

FIG. 5. Evolution of residual stress with (a) the thickness of the films and (b) the surface coverage by the nanocrystalline phase for three compositions in the transition zone. The arrows in (a) show the position of the most relaxed state (maximum) in the stress curves for the three compositions studied.

\section{B. Origin of residual stress of two-phase crystalline-amorphous nanostructured films}

Before nucleation has started, i.e., as the films are still completely amorphous, a compressive state is observed. During deposition of an amorphous film, atoms adding to the growth can pack closer than in the bulk state to increase their local electron density. This creates an excess atomic density compared to the fully coordinated bulk material. As the surface layer becomes buried and becomes bulk coordinated due to further deposition, its expansion is suppressed, leading to establish compressive stress $^{52}$. In the following, we study the evolution of stress during competitive growth between the amorphous and crystalline phases. In Fig. 5a, the evolution of residual stress with thickness for the three compositions studied is shown. When the $\mathrm{W}$ content increases, the most re-
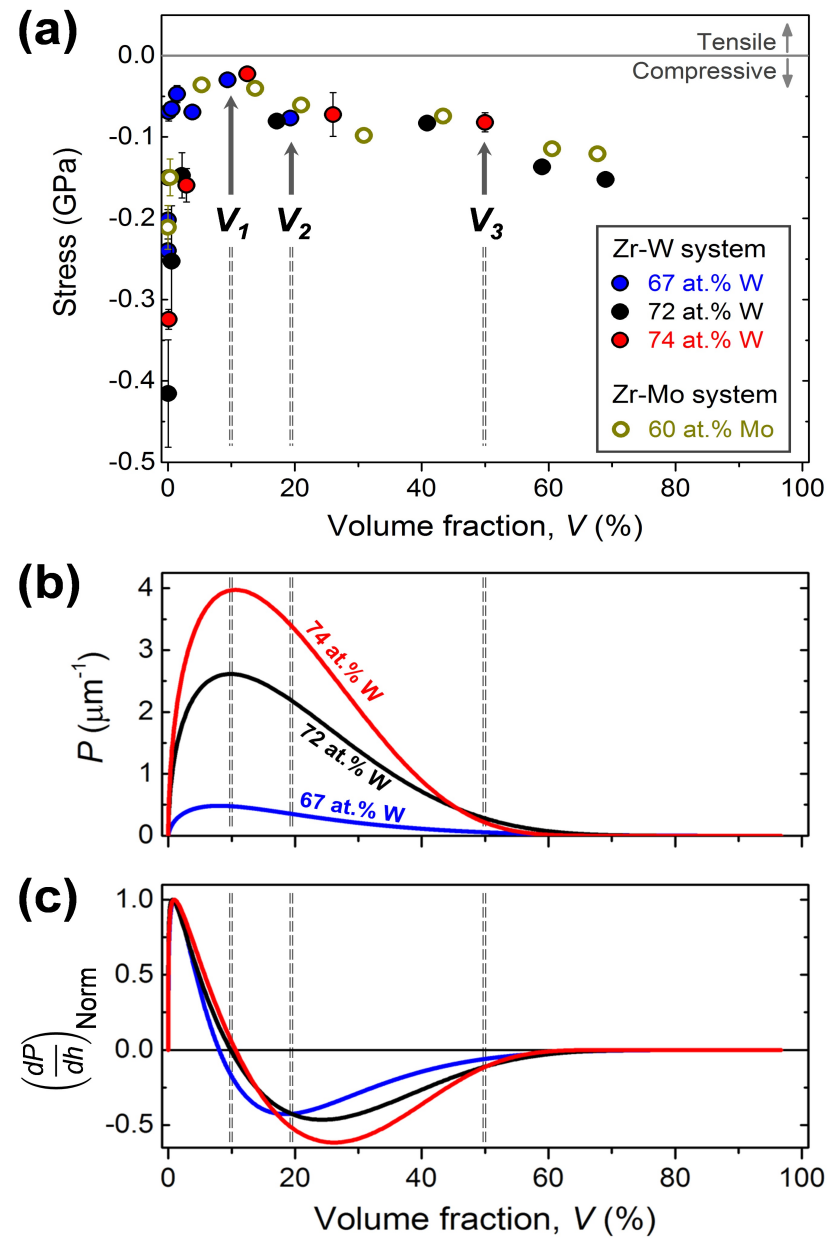

FIG. 6. Evolution of (a) the residual stress, (b) the perimeter per unit area, and (c) its derivative with the volume fraction of crystalline region inside the film. In (a) is also shown the stress-volume fraction dependency for Zr-Mo films presenting the two-phase crystalline-amorphous nanostructures. In (c), the derivative $d P / d h$ was normalized to the maximum value.

laxed state of the film is reached at a lower thickness, as indicated by the arrows in Fig. 5a. This shift to the left of the most relaxed state can be associated to the decrease of the critical thickness and increase in density of crystalline nuclei with the $\mathrm{W}$ content (see $h_{c}$ and $N_{0}$ in Table 1). Consequently, more crystalline regions appear for the same thickness (see, for example, the top view SEM images of $\sim 1 \mu \mathrm{m}$ thick films in Fig. 3b). This indicates that the stress is driven by a parameter that takes into consideration the ratio between the crystalline and amorphous phases in the film. This parameter could be $S$, which has the advantage that it can be determined directly from the analysis of the top view SEM images. In Fig. 5b, the stress-coverage curves are shown, evidencing less scattering in the stress behavior compared with the stress-thickness curves. However, considering that residual stress measurements give an "average" of the stress 
distribution over the entire film, a better parameter for guiding the stress should be $V$ (calculated from Eq. (4)), which takes in consideration the crystalline/amorphous ratio in the whole film, not just at its surface. Effectively, Fig. 6a shows that the dependency of the stress with $V$ is the same for all the studied compositions in the $\mathrm{Zr}-\mathrm{W}$ system. Furthermore, from the stress and surface coverage data reported $i^{28}$ for $\mathrm{Zr}-\mathrm{Mo}$ films presenting the nanocrystalline-amorphous competitive growth phenomenon, we determined the stress- $V$ dependency in this system. The results are also shown in Fig. 6a. Thus, the stress evolution as a function of the volume fraction follows the same behavior in the $\mathrm{Zr}-\mathrm{W}$ (for all the studied compositions) and the Zr-Mo systems. We can conclude that the factor determining the level of stress of the two-phase crystalline-amorphous nanostructures presented here is the volume fraction of the crystalline phase inside the film.

So far, the behavior of the stress has been demonstrated to be the same when plotted against $V$. However, there is another point that needs to be addressed, i.e., which factors determines the increase or decrease of stress. The stress evolution observed during this competitive growth is different from what is usually reported for single-phased thin films. Understanding which factors govern it could lead to the possibility to manipulate it in the future. There are several mechanisms associated to nucleation, growth and impingement of crystalline regions that could act on the stress behavior:

- First, the nucleation and growth of the crystalline phase leads to a tensile component of the stress to develop. This is because the crystalline phase is denser than amorphous one and, consequently, its nucleation induces a volume contraction of the film. A similar mechanism of tensile stress build-up during crystallization has been reported in $\mathrm{Zr}-\mathrm{Fe}^{53}$ and $\mathrm{Mo}-\mathrm{Si}^{54,55}$ alloys.

- Second, a careful observation of Fig. 2 and Fig. 3a reveals that new nano-columns nucleate inside crystalline regions even after they contact. These nano-columns originate from the branching of individual nano-columns of feather-like morphology, as visible in Fig. 2. The increase in the number of nano-columns per unit volume could be the origin of the conical shape of the embedded part of the crystalline regions: the lateral expansion of the crystalline regions is necessary to accommodate the generation of new nano-columns. After crystalline regions contact, this possibility of expansion is suppressed despite new nano-columns tend to be created. Therefore, the number of nano-columns per unit volume tends to increase. This mechanism could lead to gap closure between nano-columns and progressive build-up of a compressive component of the stress as individual nano-columns compete upon film growth.

Thus, when nucleation starts, the first mechanisms is dominating. Consequently, the increase in the volume fraction of the crystalline phase induces the development of a tensile component of the stress (see Fig. 6a for $\left.0<V<V_{1}\right)$. At $V_{1}(\sim 10 \%)$, this trend is reversed.
This is likely due to the proposed second mechanism to prevail. The tipping point can be correlated with the evolution of $P$ (Fig. 6b) and its derivative $d P / d h$ (Fig. $6 \mathrm{c}$ ). As followed from the figures, the tipping point corresponds to the maximum in $P$ (or zero of $d P / d h$ ). This supports the idea that $P$ serves as a measure of interaction between crystalline regions. Thus, an increase in $P$ indicates that the nucleation and growth (first mechanism) is dominating. On the contrary, a decrease in $P$ points out that the impingement (second mechanism) is prevailing.

Even though the impingement mechanism is controlling the stress of the films for volume fractions higher than $V_{1}$, a plateau in stress values can be detected from $V_{2}(\sim 20 \%)$ to $V_{3}(\sim 50 \%)$. Interestingly, the minimum of $d P / d h$ for the three compositions is reached at $\sim V_{2}$ (Fig. 6c). This indicates that this minimum is the signature of the stabilization in the stress behavior. This can be understood taking in consideration that $d P / d h$ represents the rate at which $P$ is increasing (or decreasing). Thus, when the volume fraction is such that the minimum in the $d P / d h$ curves is passed, the rate at which $P$ is decreasing because the coalescence, decrease. This indicates a reduction of interaction from this point, likely reflected in a stabilization of the stress. Finally, from $V_{3}$ most of the surface is covered by the crystalline phase (surface coverage is higher than $90 \%$ as can bee seen in the inset of Fig. 4a) and, consequently, $P$ and $d P / d h$ are almost zero. Therefore, from this volume fraction, the slight increase in the compressive component of the stress detected is associated to the growth of the crystalline phase after the entire film surface is covered.

\section{CONCLUSIONS}

In summary, we have delved into the relationship between the growth kinetics and residual stress evolution of the two-phase crystalline-amorphous nanostructures obtained in the amorphous-to-crystalline transition in sputtered deposited $\mathrm{Zr}-\mathrm{W}$ thin films. Two parameters describing the growth of these nanostructured films were introduced, i.e., the volume fraction of crystalline phase inside the film, $V$, and the perimeter per unit area of crystalline regions, $P$. We have demonstrated that $V$ is guiding the evolution of the residual stress in the crystallineamorphous competitive growth process. Furthermore, $P$ serves as a parameter accounting for the interaction between crystalline regions. An increase in $P$ indicates that nucleation and growth of crystalline regions are dominating and a decrease in $P$ points out that the impingement of crystalline regions is prevailing. Thus, the evolution of $P$ and its derivative were directly linked to residual stress measurements. 


\section{ACKNOWLEDGMENTS}

The "Université franco-allemande" (UFA) and the "Ministère de l'Enseignement Supérieur, de la Recherche et de l'Innovation" are deeply acknowledged for the PhD scholarship of Alejandro Borroto within the PhD-track in Materials Science and Engineering at UFA. The Da $\nu$ m competence center of IJL is deeply acknowledged for access to UHV magnetron sputtering deposition facility.

\section{DATA AVAILABILITY}

The data that support the findings of this study are available from the corresponding authors upon reasonable request.

\section{REFERENCES}

${ }^{1}$ J. L. Beuth and S. H. Narayan, "Residual stress-driven delamination in deposited multi-layers," Int. J. Solids Struct. 33, 65-78 (1996).

${ }^{2}$ H. H. Yu, M. Y. He, and J. W. Hutchinson, "Edge effects in thin film delamination," Acta Materialia 49, 93-107 (2001).

${ }^{3}$ T. Kitamura, H. Hirakata, and T. Itsuji, "Effect of residual stress on delamination from interface edge between nano-films," Eng. Fract. Mech. 70, 2089-2101 (2003).

${ }^{4}$ L. S. Qiu, X. D. Zhu, and K. W. Xu, "Internal stress on adhesion of hard coatings synthesized by multi-arc ion plating," Surf. Coat. Technol. 332, 267-274 (2017).

${ }^{5}$ T. Karabacak, C. R. Picu, J. J. Senkevich, G. C. Wang, and T. M. Lu, "Stress reduction in tungsten films using nanostructured compliant layers," J. Appl. Phys. 96, 5740-5746 (2004).

${ }^{6}$ T. Karabacak, J. J. Senkevich, G. C. Wang, and T. M. Lu, "Stress reduction in sputter deposited films using nanostructured compliant layers by high working-gas pressures," J. Vac. Sci. Technol. A 23, 986-990 (2005).

${ }^{7}$ L. Karlsson, L. Hultman, and J. E. Sundgren, "Influence of residual stresses on the mechanical properties of $\mathrm{TiC}_{\mathrm{x}} \mathrm{N}_{1-\mathrm{x}}(\mathrm{x}=0$, $0.15,0.45)$ thin films deposited by arc evaporation," Thin Solid Films 371, 167-177 (2000).

${ }^{8}$ G. Cheng, D. Han, C. Liang, X. Wu, and R. Zheng, "Influence of residual stress on mechanical properties of TiAlN thin films," Surf. Coat. Technol. 228, S328-S330 (2013).

${ }^{9}$ P. Zou, W. Yu, and J. A. Bain, "Influence of stress and texture on soft magnetic properties of thin films," IEEE Trans. Magn. 38, 3501-3520 (2002).

${ }^{10} \mathrm{~S}$. Guan and B. J. Nelson, "Electrodeposition of low residual stress CoNiMnP hard magnetic thin films for magnetic MEMS actuators," J. Magn. Magn. Mater. 292, 49-58 (2005).

${ }^{11}$ P. Tyagi and A. G. Vedeshwar, "Effect of residual stress on the optical properties of $\mathrm{CdI}_{2}$ films," Phys. Rev. B 66, 075422 (2002).

${ }^{12}$ B. Sarma and B. K. Sarma, "Role of residual stress and texture of $\mathrm{ZnO}$ nanocrystals on electrooptical properties of $\mathrm{ZnO} / \mathrm{Ag} / \mathrm{ZnO}$ multilayer transparent conductors," J. Alloys Compd. 734, 210219 (2018).

${ }^{13}$ B. A. Movchan and A. V. Demchishin, "Structure and properties of thick condensates of nickel, titanium, tungsten, aluminum oxides, and zirconium dioxide in vacuum," Fiz. Metal. Metalloved. 28, 653 (1969).

${ }^{14}$ J. A. Thornton, "Influence of apparatus geometry and deposition conditions on the structure and topography of thick sputtered coatings," J. Vac. Sci. Technol. 11, 666-670 (1974).
${ }^{15}$ J. A. Thornton, "High rate thick film growth," Ann. Rev. Mater. Sci. 7, 239-260 (1977).

${ }^{16}$ A. Anders, "A structure zone diagram including plasma-based deposition and ion etching," Thin Solid Films 518, 4087-4090 (2010).

${ }^{17}$ D. W. Hoffman and J. A. Thornton, "Internal stresses in sputtered chromium," Thin Solid Films 40, 355-363 (1977).

${ }^{18} \mathrm{~J}$. A. Thornton and D. W. Hoffman, "Internal stresses in titanium, nickel, molybdenum, and tantalum films deposited by cylindrical magnetron sputtering," J. Vac. Sci. Technol. 14, 164168 (1977).

${ }^{19}$ D. W. Hoffman and J. A. Thornton, "The compressive stress transition in $\mathrm{Al}, \mathrm{V}, \mathrm{Zr}, \mathrm{Nb}$ and $\mathrm{W}$ metal films sputtered at low working pressures," Thin Solid Films 45, 387-396 (1977).

${ }^{20}$ D. W. Hoffman and J. A. Thornton, "Internal stresses in Cr, Mo, Ta, and Pt films deposited by sputtering from a planar magnetron source," J. Vac. Sci. Technol. 20, 355-358 (1982).

${ }^{21}$ J. A. Thornton and D. W. Hoffman, "Stress-related effects in thin films," Thin Solid Films 171, 5-31 (1989).

${ }^{22} \mathrm{H}$. Windischmann, "Intrinsic stress in sputter-deposited thin films," Crit. Rev. Solid State Mater. Sci. 17, 547-596 (1992).

${ }^{23}$ E. Chason, B. W. Sheldon, L. B. Freund, J. A. Floro, and S. J. Hearne, "Origin of compressive residual stress in polycrystalline thin films," Phys. Rev. Lett. 88, 156103 (2002).

${ }^{24} \mathrm{E}$. Chason, "A kinetic analysis of residual stress evolution in polycrystalline thin films," Thin Solid Films 526, 1-14 (2012).

${ }^{25}$ E. Chason, M. Karlson, J. J. Colin, D. Magnfält, K. Sarakinos, and G. Abadias, "A kinetic model for stress generation in thin films grown from energetic vapor fluxes," J. Appl. Phys. 119, 145307 (2016).

${ }^{26}$ G. Abadias, E. Chason, J. Keckes, M. Sebastiani, G. B. Thompson, E. Barthel, G. L. Doll, C. E. Murray, C. H. Stoessel, and L. Martinu, "Stress in thin films and coatings: Current status, challenges, and prospects," J. Vac. Sci. Technol. A 36, 020801 (2018).

${ }^{27} \mathrm{P}$. Jagtap and E. Chason, "A unified kinetic model for stress relaxation and recovery during and after growth interruptions in polycrystalline thin films," Acta Materialia 193, 202-209 (2020).

${ }^{28}$ A. Borroto, S. Bruyère, S. Migot, J. F. Pierson, T. Gries, F. Mücklich, and D. Horwat, "Controlling surface morphology by nanocrystalline/amorphous competitive self-phase separation in thin films: Thickness-modulated reflectance and interference phenomena," Acta Materialia 181, 78-86 (2019).

${ }^{29}$ A. Borroto, A. C. García-Wong, S. Bruyère, S. Migot, D. Pilloud, J. F. Pierson, F. Mücklich, and D. Horwat, "Composition-driven transition from amorphous to crystalline films enables bottomup design of functional surfaces," Applied Surface Science 538, 148133 (2021).

${ }^{30}$ V. Kolkovsky, J. U. Schmidt, and S. Döring, "Electrical and structural properties of direct current magnetron sputtered amorphous TiAl thin films," Thin Solid Films 669, 169-173 (2019).

${ }^{31}$ R. Gago, M. Vinnichenko, A. Redondo-Cubero, Z. Czigány, and L. Vázquez, "Surface morphology of heterogeneous nanocrystalline rutile/amorphous anatase $\mathrm{TiO}_{2}$ films grown by reactive pulsed magnetron sputtering," Plasma Process. Polym. 7, 813823 (2010).

${ }^{32}$ V. Brien, P. Miska, B. Bolle, and P. Pigeat, "Columnar growth of AlN by r.f. magnetron sputtering: Role of the $\{10 \overline{1} 3\}$ planes," J. Crystal Growth 307, 245-252 (2007).

${ }^{33}$ P. Zeman, S. Haviar, and M. Črvená, "Self-formation of dual glassy-crystalline structure in magnetron sputtered W-Zr films," Vacuum 187, 110099 (2021).

${ }^{34}$ G. M. Janssen, M. M. Abdalla, F. van Keulen, B. R. Pujada, and B. van Venrooy, "Celebrating the 100th anniversary of the stoney equation for film stress: Developments from polycrystalline steel strips to single crystal silicon wafers," Thin Solid Films 517, 1858-1867 (2009).

${ }^{35}$ D. Horwat, M. Dehmas, E. Aubry, J. Zollinger, S. Migot, and J. F. Pierson, "Properties of nanocrystalline and nanocomposite $\mathrm{W}_{\mathrm{x}} \mathrm{Zr}_{1-\mathrm{x}}$ thin films deposited by co-sputtering," Intermetallics 
17, 421-426 (2009).

${ }^{36}$ D. Horwat, E. Jimenez-Pique, J. F. Pierson, S. Migot, M. Dehmas, and M. Anglada, "High hardness, low young's modulus and low friction of nanocrystalline $\mathrm{ZrW}_{2}$ laves phase and $\mathrm{Zr}_{1-\mathrm{x}} \mathrm{W}_{\mathrm{x}}$ thin films," J. Phys. Chem. Solids 73, 554-558 (2012).

${ }^{37}$ A. Borroto, S. Bruyère, N. Thurieau, C. Gendarme, E. JimenezPique, J. J. Roa, J. F. Pierson, F. Mücklich, and D. Horwat, "Structural and mechanical properties of $\mathrm{Zr}_{1-\mathrm{x}} \mathrm{Mo}_{\mathrm{x}}$ thin films: From the nano-crystalline to the amorphous state," J. Alloys Compd. 729, 137-143 (2017).

${ }^{38}$ Z. Z. Tang, J. H. Hsieh, S. Y. Zhang, C. Li, and Y. Q. Fu, "Phase transition and microstructure change in Ta-Zr alloy films by co-sputtering," Surface and Coatings Technology 198, 110113 (2005).

${ }^{39} \mathrm{P}$. Sharma, H. Kimura, and A. Inoue, "Magnetic behavior of cosputtered $\mathrm{Fe}-\mathrm{Zr}$ amorphous thin films exhibiting perpendicular magnetic anisotropy," Physical Review B 78, 134414 (2008).

${ }^{40}$ D. M. King, S. C. Middleburgh, A. Y. Liu, H. A. Tahini, G. R. Lumpkin, and M. B. Cortie, "Formation and structure of $\mathrm{V}-\mathrm{Zr}$ amorphous alloy thin films," Acta Materialia 83, 269-275 (2015).

${ }^{41}$ M. Apreutesei, F. Steyer, A. Billard, L. Joly-Pottuz, and C. Esnouf, " $\mathrm{Zr}-\mathrm{Cu}$ thin film metallic glasses: An assessment of the thermal stability and phases' transformation mechanisms," Journal of Alloys and Compounds 619, 284-292 (2015).

${ }^{42}$ F. Sanchette, T. H. Loi, A. Billard, and C. Frantz, "Structureproperties relationship of metastable $\mathrm{Al}-\mathrm{Cr}$ and $\mathrm{Al}-\mathrm{Ti}$ alloys deposited by r.f. magnetron sputtering: role of nitrogen," Surface and Coatings Technology 74-75, 903-909 (1995).

${ }^{43}$ E. A. Jägle and E. J. Mittemeijer, "The kinetics of grainboundary nucleated phase transformations: Simulations and modelling," Acta Materialia 59, 5775-5786 (2011).

${ }^{44}$ A. N. Kolmogorov, "On the statistical theory of the crystallization of metals," Bull. Acad. Sci. USSR, Math. Ser. 1, 355-359 (1937).
${ }^{45}$ W. A. Johnson and R. F. Mehl, "Reaction kinetics in processes of nucleation and growth," Trans. Am. Inst. Min. Eng. 135, 416458 (1939).

${ }^{46}$ M. Avrami, "Kinetics of phase change. i general theory," J. Chem. Phys. 7, 1103-1112 (1939).

${ }^{47}$ M. Avrami, "Kinetics of phase change. ii transformation-time relations for random distribution of nuclei," J. Chem. Phys. 8, 212-224 (1940).

${ }^{48}$ M. Avrami, "Granulation, phase change, and microstructure kinetics of phase change. iii," J. Chem. Phys. 9, 177-184 (1941).

${ }^{49}$ A. T. W. Kempen, F. Sommer, and E. J. Mittemeijer, "Determination and interpretation of isothermal and non-isothermal transformation kinetics; the effective activation energies in terms of nucleation and growth," J. Mater. Sci. 37, 1321-1332 (2002).

${ }^{50}$ E. J. Mittemeijer and F. Sommer, "Solid state phase transformation kinetics: a modular transformation model," Z. Metallkd. 93, 5 (2002).

${ }^{51}$ F. Liu, F. Sommer, C. Bos, and E. J. Mittemeijer, "Analysis of solid state phase transformation kinetics: models and recipes," Int. Mater. Rev. 52, 193-212 (2007).

52 J. A. Floro, P. G. Kotula, S. C. Seel, and D. J. Srolovitz, "Origins of growth stresses in amorphous semiconductor thin films," Phys. Rev. Lett. 91, 096101 (2003).

${ }^{53}$ S. G. Mayr and K. Samwer, "Surface morphology, stress, and volume change during growth and crystallizationof interfacestabilized amorphous $\mathrm{Fe}_{100-\mathrm{x}} \mathrm{Zr}_{\mathrm{x}}$," Physical Review B 65, 115408 (2002).

${ }^{54}$ A. Fillon, G. Abadias, A. Michel, C. Jaouen, and P. Villechaise, "Influence of phase transformation on stress evolution during growth of metal thin films on silicon," Phys. Rev. Lett. 104, 096101 (2010).

${ }^{55}$ B. Krause, G. Abadias, A. Michel, P. Wochner, S. Ibrahimkutty, and T. Baumbach, "Direct observation of the thickness-induced crystallization and stress build-up during sputter-deposition of nanoscale silicide films," ACS Appl. Mater. Interfaces 8, 3488834895 (2016). 